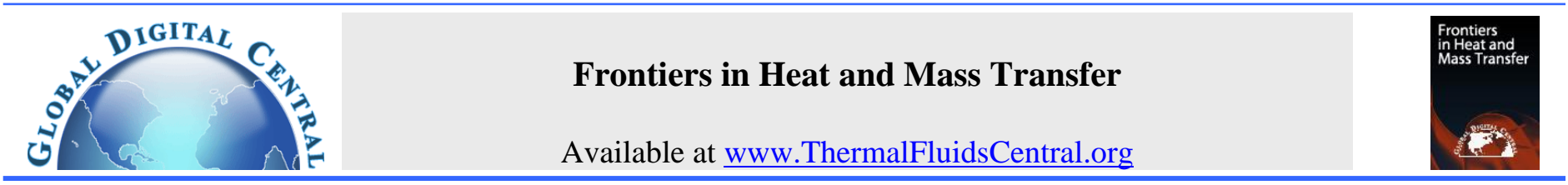

\title{
IMPACT OF VARIABLE LIQUID PROPERTIES ON PERISTALTIC MECHANISM OF CONVECTIVELY HEATED JEFFREY FLUID IN A SLIPPERY ELASTIC TUBE
}

\author{
B.B. Divya ${ }^{a}$, G. Manjunatha ${ }^{a}, \dagger$, C. Rajashekhar ${ }^{\mathrm{a}}$, Hanumesh Vaidya $^{\mathrm{b}}$, K.V. Prasad $^{\mathrm{c}}$ \\ ${ }^{a}$ Department of Mathematics, Manipal Institute of Technology, Manipal Academy of Higher Education, Manipal, Karnataka, 576104, India \\ ${ }^{\mathrm{b}}$ Department of Mathematics, SSA Government First Grade College (Autonomous), Ballari, Karnataka, 583101, India \\ ${ }^{\mathrm{c}}$ Department of Mathematics, Vijayanagara Srikrishnadevaraya University, Ballari, Karnataka, 583105, India
}

\begin{abstract}
The present paper examines the peristaltic mechanism of a Jeffrey fluid through an elastic tube. The influence of velocity slip, convective boundary conditions, and variable liquid properties are taken into account. Closed form solutions are obtained for velocity, flux and temperature fields. In order to linearize the temperature equation, perturbation technique is employed. Also, the flux is determined theoretically via Rubinow and Keller and Mazumdar approach and the results are compared graphically. The effects of various vital parameters on the fluid flow are sketched and analyzed graphically. The findings emphasize the importance of elastic parameters in enhancing the flux of a non-Newtonian fluid. Moreover, a rise in the variable viscosity results in an increase in the velocity and temperature, whereas a drop in the flux is observed. Trapping phenomena reveals an increase in the volume of the bolus for increasing values of the variable viscosity and velocity slip parameter.
\end{abstract}

Keywords: Elastic parameter; Jeffrey parameter; thermal conductivity; variable viscosity

\section{INTRODUCTION}

Peristalsis is the fluid flow mechanism through which the fluid is transported through a distensible tube by means of progressive waves of expansion and contraction. Latham (1966) was the first person to investigate the peristaltic mechanism in the transport of urine through the ureter. Since then, numerous investigations have been carried out to study the process of peristaltic transport of fluids, both Newtonian and non- Newtonian. Specifically, the analysis of non-Newtonian fluids is of more significance in the biological systems. Keeping this in mind, Mernone et al. (2002) studied the peristaltic flow of physiological fluids by using the generalized form of the Casson model. Recently, Rajashekhar et al. (2018a) investigated the peristaltic transport of blood by using HerschelBulkley fluid. They also discussed the physiological behavior of Newtonian, power-law and Bingham fluids. Among the several non-Newtonian models, Jeffrey model is more significant in describing the flow of blood in arteries. The studies on the use of Jeffrey model was carried out by Hayat et al. (2007). Later on, numerous researchers have investigated the peristaltic mechanism of Jeffrey fluid in different geometrical configurations (Bhatti and Abbas (2016); Selvi et al. (2017)).

Most of the studies carried out on peristalsis consider the fluid to be of constant viscosity. Though this consideration gives satisfactory results for the peristaltic transport of urine through the ureter, it is unable to provide accurate results for the peristaltic motion of blood through small blood vessels and arteries. This inability is due to the fact that the viscosity of blood varies with the thickness of the small arteries. The concentration of blood cells in whole blood varies across the tube. Thus, the viscosity of blood near the walls of the arteries have a lower value. Srivastava et al. (1983) analyzed the effects of variable viscosity on the peristaltic transport of fluids flowing through a non-uniform geometry. The peristaltic pumping of a Newtonian fluid with varying viscosity and zero Reynolds number was studied by El Naby et al. (2004) under the influence of an inserted endoscope. Hayat and Ali (2008) presented a mathematical model to scrutinize the effects of variable viscosity on the different parameters of flow, such as flow rate, frictional forces and pressure rise in an asymmetric channel. Due to the widespread applications of heat transfer in engineering and medical fields, researchers have shown interest in studies on heat transfer during the peristaltic transport of different types of fluids. The variable thermal conductivity of fluids provide a better approximation of the physiological fluid flow, especially the blood flowing through arteries (Prasad et al. (2017); Prasad et al. (2018a); Prasad et al. (2018b)). Moreover, transfer of heat can take place by three different modes: conduction, convection, and radiation. Among these, convection mode of heat transfer is more prominent in blood flow. Convection is the process by which heat is transferred due to the movement of particles of the fluid. In biological systems, the process of hemodialysis and oxygenation of blood involve the transfer of heat by means of convection. Hence, investigations have been done by consider-

${ }^{\dagger}$ Corresponding author. Email: gudekote_m@rediffmail.com 
ing the convective boundary conditions for classical and biological fluids in different geometries and assumptions (Boulahia et al. (2018); Hayat et al. (2013); Hayat et al. (2016); Mebarek-Oudina and Bessaih (2016); Mebarek-Oudina (2017); Munir et al. (2014); Wakif et al. (2018a); Wakif et al. (2018b); Wakif et al. (2018c)).

The above studies on peristaltic mechanism have the imposition of no-slip condition at the walls of the arteries. However, this is not sufficient to completely describe the behavior of the blood flow through them. The fluid flow exhibits some velocity slip at the walls. Moreover, slip effects are more pronounced in the non-Newtonian behavior of blood. This concept of velocity slip has been accounted for by many researchers in the investigations carried out on peristalsis of fluids along with the effects of heat transfer (Hayat et al. (2010); Sankad and Patil (2018)). Sinha et al. (2015) incorporated the influence of variable viscosity, velocity slip and thermal slip in their attempt to provide better theoretical estimates of the flow parameters of Newtonian fluid exhibiting peristaltic motion. Their findings concluded that the velocity of fluid in the central region decreases as the value of the velocity-slip parameter increases. The nonNewtonian consideration for such studies was taken into account by Javed et al. (2016). Investigations were further carried out by Rajashekhar et al. (2018b) with the variable liquid properties and the effects of convective boundary conditions on the peristalsis of a Casson fluid fluid through an inclined porous tube.

The primary function of the arteries is to carry the blood pumped by the heart to the different parts of the body. Thus, arteries are the first among the blood vessels to receive blood pumped at high pressure from the heart. For the arteries to be able to withstand this high pressure, their walls are thick and elastic. The elastic nature of the arterial walls helps in its expansion during high blood pressure and then regains to its original shape and size when the heart relaxes between the systole and diastole. Thus, due consideration should be given to the elastic property of the arterial walls to study the flow of blood in arteries. Accordingly, several researchers have investigated the peristaltic mechanism of different fluids through elastic tubes under various boundary conditions (Manjunatha and Choudhary (2018); Rajashekhar et al. (2018c); Srinivas et al. (2017); Vaidya et al. (2018a); Vaidya et al. (2018b); Vajravelu et al. (2015); Vajravelu et al. (2016)).

The present paper aims to investigate the peristaltic flow of a Jeffrey fluid through an elastic tube. The influence of velocity slip, convective boundary conditions, and variable liquid properties are considered. To the best of authors' knowledge, no attempts have been done in this direction. Closed-form solutions are obtained for the velocity, flux, and temperature expressions. Also, the flux is determined theoretically by two different approaches with the help of MATLAB. The effects of various pertinent flow parameters are graphed and analyzed.

\section{MATHEMATICAL FORMULATIONS}

Consider the flow through an axisymmetric elastic tube of radius $a$ (see Fig. 1). The chosen cylindrical coordinate system be $(R, \Theta, Z)$. A sinusoidal wave train of wavelength $\lambda$ and amplitude $b$ is taken at upper wall of the tube. At any point on the axis of the tube, the instantaneous radius of the tube is given by

$$
h^{\prime}(Z, t)=a+b \sin \left[\frac{2 \pi}{\lambda}(Z-c t)\right] .
$$

The length of the tube is assumed to be an integral multiple of the wavelength $\lambda$. Pressure applied at the ends of the tube is such that a constant pressure difference is maintained across it. Owing to the unsteady flow in the laboratory frame of reference $(R, \Theta, Z)$, a wave frame $(r, \theta, z)$ moving away from the fixed frame at a constant velocity $c$ is considered. The transformations between these two frames are

$$
r=R, z=Z-c t, \psi=\Psi-\frac{R^{2}}{2}, p(Z, t)=P(z),
$$

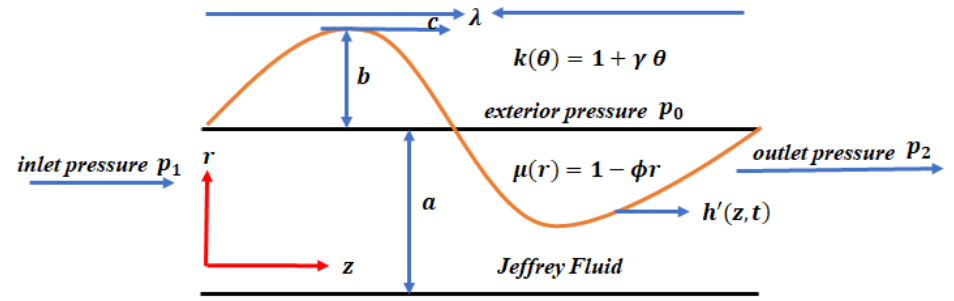

Fig. 1 Geometry of the physical model.

where $P, p, \Psi, \psi$ are the pressures and streamlines in the fixed and wave frames respectively. Pressure is taken to be uniform at any location along the axis of the tube under the assumption of long wavelength approximation. Consider the non-dimensional variables as given below (Rajashekhar et al. (2018c)) :

$$
\begin{gathered}
\bar{r}=\frac{r}{h}, \bar{z}=\frac{z}{\lambda}, \bar{t}=\frac{c t}{\lambda}, \bar{p}=\frac{p h^{\prime}}{\lambda c \mu_{0}}, \epsilon=\frac{b}{a}, \operatorname{Pr}=\frac{\mu_{0} c_{p}}{k}, \bar{u}=\frac{u}{c}, \\
\bar{w}=\frac{w}{c}, \bar{\psi}=\frac{\psi}{\pi a^{2} c}, u=-\frac{1}{r} \frac{\partial \psi}{\partial z}, w=\frac{1}{r} \frac{\partial \psi}{\partial r}, \theta=\frac{T-T_{0}}{T_{0}}, \\
E c=\frac{c^{2}}{c_{p} T_{0}}, \delta=\frac{a}{\lambda}, R e=\frac{\rho c a}{\mu_{0}}, \bar{\mu}(r)=\frac{\mu(r)}{\mu_{0}}, N=E c \times \operatorname{Pr},
\end{gathered}
$$

where the symbols are as given in the nomenclature.

The momentum and energy equations governing the flow are (Rajashekhar et al. (2018c)) :

$$
\begin{aligned}
& \operatorname{Re} \delta\left(u \frac{\partial}{\partial r}+w \frac{\partial}{\partial z}\right) w=-\frac{\partial p}{\partial z}+\frac{1}{r} \frac{\partial}{\partial r}\left(r \tau_{r z}\right)+\delta \frac{\partial}{\partial r}\left(\tau_{z z}\right),(4) \\
& \operatorname{Re} \delta^{3}\left(u \frac{\partial}{\partial r}+w \frac{\partial}{\partial z}\right) u=-\frac{\partial p}{\partial r}+\frac{\delta}{r} \frac{\partial}{\partial r}\left(r \tau_{r r}\right)+\delta^{2} \frac{\partial}{\partial r}\left(\tau_{r z}\right)(5) \\
& \operatorname{Re} \delta \operatorname{Pr}\left(u \frac{\partial}{\partial r}+w \frac{\partial}{\partial z}\right) \theta=\operatorname{EcPr}\left(\delta \frac{\partial u}{\partial r} \tau_{r r}+\frac{\partial w}{\partial r} \tau_{r z}\right. \\
& \left.+\delta^{2} \frac{\partial u}{\partial z} \tau_{z r}+\tau_{z z} \frac{\partial w}{\partial r} \delta\right)+\frac{\partial^{2} \theta}{\partial r^{2}}+\frac{1}{r} \frac{\partial \theta}{\partial r}+\delta^{2} \frac{\partial^{2} \theta}{\partial z^{2}}
\end{aligned}
$$

With the help of $R e=0$ and $\delta<<1$, the Eqs. (4) - (6) reduce to

$$
\begin{aligned}
\frac{1}{r} \frac{\partial}{\partial r}\left(r \tau_{r z}\right) & =-\frac{\partial p}{\partial z} \\
0 & =\frac{\partial p}{\partial r} \\
\frac{1}{r} \frac{\partial}{\partial r}\left(r k(\theta) \frac{\partial \theta}{\partial r}\right) & =N\left(-\frac{\partial w}{\partial r} \tau_{r z}\right) .
\end{aligned}
$$

The constitutive non-dimensional equation for a Jeffrey fluid is given by

$$
\tau_{r z}=\frac{\mu(r)}{1+\lambda_{1}}\left(-\frac{\partial w}{\partial r}\right)
$$

where $\lambda_{1}$ is the Jeffrey parameter.

The variations in viscosity and thermal conductivity are given by the following relations :

$$
\begin{aligned}
& \mu(r)=1-\phi r, \quad \phi<<1 \\
& k(\theta)=1+\beta \theta, \quad \beta<<1
\end{aligned}
$$

where $\beta$ is the coefficient of thermal conductivity and $\phi$ is the coefficient of variable viscosity. 
The corresponding non-dimensional boundary conditions are (Vaidya et al. (2018b))

$$
\begin{aligned}
w+\alpha \frac{\partial w}{\partial r} & =0 \text { at } r=h^{\prime}, \\
\tau_{r z} & =0 \text { at } r=0, \\
(1+\beta) \frac{\partial \theta}{\partial r}+\gamma \theta & =0 \text { at } r=h^{\prime}, \\
\frac{\partial \theta}{\partial r} & =0 \text { at } r=0,
\end{aligned}
$$

where $\gamma$ is the Biot number.

\section{METHOD OF SOLUTION}

On substituting Eqs. (10) and (11) in Eq. (7) and solving for velocity $w$ by using the boundary conditions (13a) and (13b), we obtain an expression for velocity as given below:

$$
w=\frac{P\left(1+\lambda_{1}\right)}{2}\left[\frac{h^{\prime} \alpha}{1-\phi r}+\frac{r-h^{\prime}}{\phi}+\frac{1}{\phi^{2}} \log \left(\frac{1-\phi r}{1-\phi h^{\prime}}\right)\right] .
$$

The volumetric flow rate $Q$ is given by

$$
\begin{aligned}
Q= & 2 \int_{0}^{h} w r d r \\
= & \frac{P h^{\prime}\left(1+\lambda_{1}\right)}{12 \phi^{3}}\left[4 h^{\prime 2} \phi^{2}-3 h^{\prime} \phi\left(1+2 h^{\prime} \phi\right)-6\left(1+2 \alpha h^{\prime} \phi^{2}\right)-\right. \\
& \left.6\left(1+2 \alpha h^{\prime} \phi^{2}\right) \log \left(1-h^{\prime} \phi\right)\right]
\end{aligned}
$$

Integrating Eq. (14) and using the condition $\psi=\frac{q}{2}$ at $r=h^{\prime}$, we obtain the expression for stream function as

$$
\begin{aligned}
\psi= & \frac{q}{2}+\frac{P\left(1+\lambda_{1}\right)}{24 \phi^{4}}\left\{6\left(1+2 \alpha h^{\prime} \phi^{2}\right) \log \left(1-h^{\prime} \phi\right)-6\left(1+2 \alpha h^{\prime} \phi^{2}\right)\right. \\
& \log (1-r \phi)+\phi\left[( h ^ { \prime } - r ) \left[6+3\left(h^{\prime}+r\right) \phi+2\left(6 \alpha h^{\prime}+h^{\prime 2}+h^{\prime} r\right.\right.\right. \\
& \left.\left.\left.\left.-2 r^{2}\right) \phi^{2}\right]+6 r^{2} \phi \log \left(\frac{-1+r \phi}{-1+h^{\prime} \phi}\right)\right]\right\} .
\end{aligned}
$$

Due to the non-linear term present in Eq. (9), the exact solution cannot be obtained for the temperature. Moreover, the value of $\beta$ is found to be small in most of the practical applications. This enables us to apply perturbation method for its solution.

\subsection{Perturbation method}

Perturbation method is used to linearise the complex form of heat equation such as Eq. (9). The appropriate series form for the temperature is

$$
\theta=\sum_{n=0}^{\infty} \beta^{n} \theta_{n} .
$$

\section{Zeroth order solution}

Introducing series solution of the parameters defined in Eq. (18) into Eq. (9) and arranging the coefficients of $\beta$, the first characteristic equation of the temperature $\theta_{0}$ is obtained as:

$$
\frac{1}{r} \frac{\partial}{\partial r}\left(r k\left(\theta_{0}\right) \frac{\partial \theta_{0}}{\partial r}\right)=N\left(-\frac{\partial w}{\partial r} \tau_{r z}\right) .
$$

The zero-order solution of the temperature $\theta$ with respect to boundary condition around the wall

$$
\begin{aligned}
(1+\beta) \frac{\partial \theta_{0}}{\partial r}+\gamma \theta_{0} & =0 \text { at } r=h^{\prime} \\
\frac{\partial \theta_{0}}{\partial r} & =0 \text { at } r=0
\end{aligned}
$$

is given by

$$
\begin{array}{r}
\theta_{0}=\frac{N P^{2}\left(1+\lambda_{1}\right)}{24 \phi^{4}}\left[\frac{(1+\beta)\left[a_{1} \phi+a_{2} \log \left(1-h^{\prime} \phi\right)\right]}{h^{\prime} \gamma}+a_{3}+\right. \\
6 a_{4} \phi\left(h^{\prime}-r\right)+a_{5}\left(\log \left(\frac{h^{\prime}}{1-h^{\prime} \phi}\right)+\log \left(\frac{1-r \phi}{r}\right)\right)- \\
\left.a_{2}\left[\operatorname{polylog}\left(2, h^{\prime} \phi\right)-\operatorname{polylog}(2, r \phi)\right]-a_{5}\right],
\end{array}
$$

where,

$$
\begin{aligned}
& a_{1}=3 h^{\prime 2} \phi+2 h^{\prime 3} \phi^{2}+6\left(h^{\prime}+2 \alpha h^{\prime 2} \phi^{2}\right)+ \\
& \frac{3 \alpha h^{\prime} \phi\left[4+\alpha h^{\prime} \phi^{2}-2 \phi h^{\prime}\left(2+\alpha h^{\prime} \phi^{2}\right)\right]}{\left(h^{\prime} \phi-1\right)^{2}}, \\
& a_{2}=6\left(1+4 \alpha h^{\prime} \phi^{2}\right) \text {, } \\
& a_{3}=\frac{3 h^{\prime 2} \phi^{2}}{2}+\frac{2 h^{\prime 3} \phi^{3}}{3}+\frac{3 \alpha^{2} h^{\prime 2} \phi^{4}}{h^{\prime} \phi-1}, \\
& a_{4}=1+2 \alpha h^{\prime} \phi^{2} \text {, } \\
& a_{5}=3 \alpha h^{\prime} \phi^{2}\left(4+\alpha h^{\prime} \phi^{2}\right) \text {, } \\
& a_{6}=\frac{3 r^{2} \phi^{2}}{2}+\frac{2 r^{3} \phi^{3}}{3}+\frac{3 \alpha^{2} h^{\prime 2} \phi^{4}}{r \phi-1} \text {. }
\end{aligned}
$$

First order solution

Applying the above method in Eq. (9), the characteristic equation of the temperature $\theta_{1}$ is written as

$$
\begin{aligned}
\frac{1}{r} \frac{\partial}{\partial r}\left(r k\left(\theta_{1}\right) \frac{\partial \theta_{1}}{\partial r}\right) & =N\left(-\frac{\partial w}{\partial r} \tau_{r z}\right), \\
(1+\beta) \frac{\partial \theta_{1}}{\partial r}+\gamma \theta_{1} & =0 \text { at } r=h^{\prime}, \\
\frac{\partial \theta_{1}}{\partial r} & =0 \text { at } r=0 .
\end{aligned}
$$

Solving Eq. (22) with the help of boundary conditions prescribed by Eqs. (23a) and (23b), we obtain the first order solution as

$$
\theta_{1}=\left(\theta_{0}\right)^{2} .
$$

Substituting Eqs. (21) and (24) in Eq. (18) and neglecting the terms higher than $O(\beta)$, we obtain the solution for temperature.

\subsection{Theoretical determination of flux}

Consider an elastic tube of length $L$ and radius $h(z, t)=h^{\prime}(z, t)+$ $h^{\prime \prime}(z)$, where $h^{\prime}(z, t)$ is the radius of the tube due to the peristaltic motion and $h^{\prime \prime}(z)$ is the radius due to the elasticity of the tube. Let $p_{1}, p_{2}$ and $p_{0}$ be the inlet, outlet and exterior pressures respectively. Let $z$ be the distance from the inlet end. Then $p(z)$ is the pressure inside the tube at any point $z$ in the tube. $p(z)$ decreases from $p(0)=p_{1}$ to $p(L)=p_{2}$. The expansion and contraction of the elastic tube at $z$ happens due to the transmural pressure difference $\left[p(z)-p_{0}\right]$ and results in deformation in the cross-section of the tube. Hence, the conductivity $\sigma_{1}$ at any point in the tube depends on the transmural pressure difference. The relation between the flux and the pressure gradient is assumed to be

$$
Q=\sigma_{1}\left(p-p_{0}\right)\left(\frac{\partial p}{\partial z}\right) .
$$

On comparing Eqs. (16) and (25), we observe that

$$
\begin{aligned}
\sigma_{1}\left(p-p_{0}\right)= & \frac{h\left(1+\lambda_{1}\right)}{12 \phi^{3}}\left[4 h^{2} \phi^{2}-3 h \phi(1+2 h \phi)-6(1+\right. \\
& \left.\left.2 \alpha h \phi^{2}\right)-6\left(1+2 \alpha h \phi^{2}\right) \log (1-h \phi)\right] .
\end{aligned}
$$




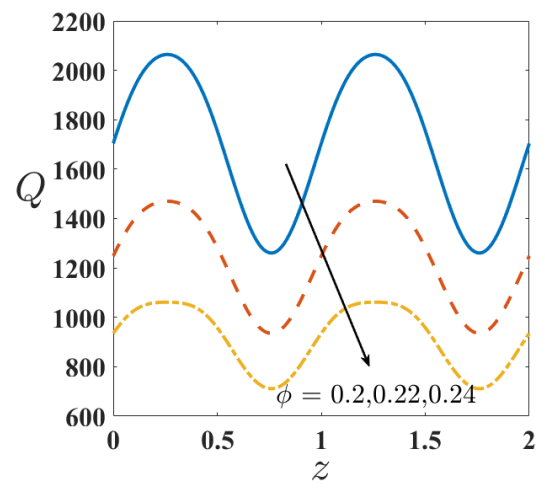

(a)

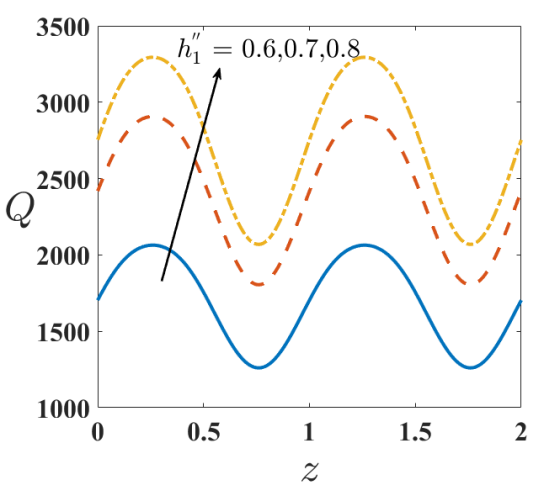

(d)

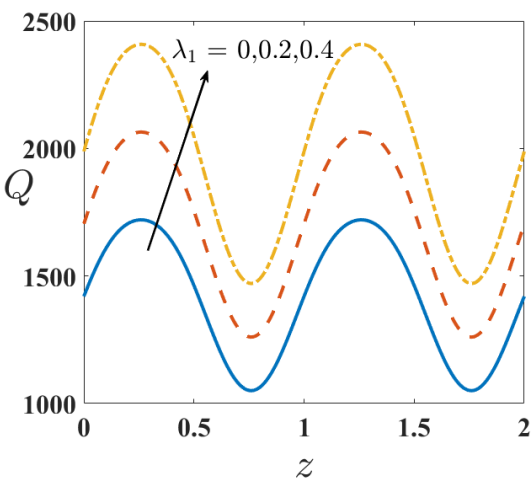

(b)

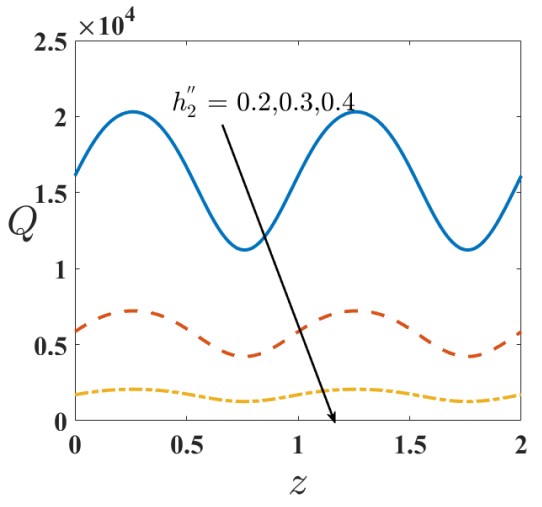

(e)

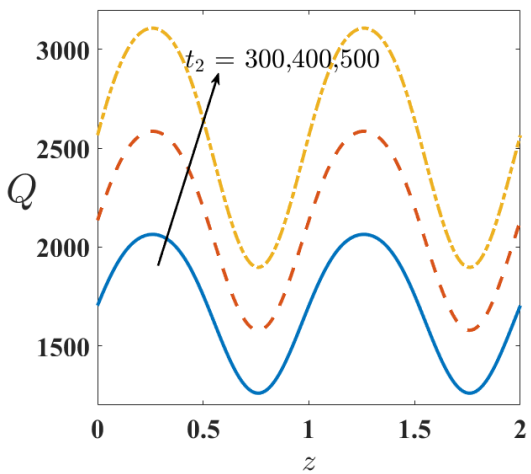

$(\mathrm{g})$

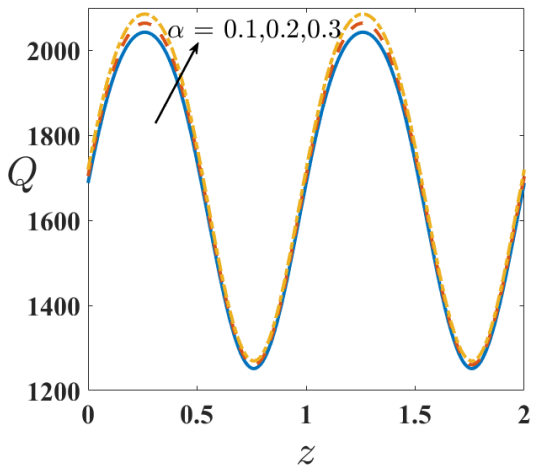

(c)

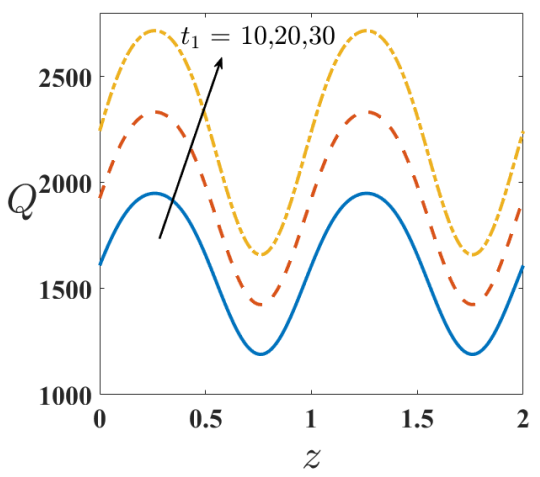

(f)

Fig. 2 Flux $(Q)$ for different values of (a) variable viscosity $(\phi)$, (b) Jeffrey parameter $\left(\lambda_{1}\right)$, (c) velocity slip parameter $(\alpha)$, (d) inlet elastic radius $\left(h_{1}^{\prime \prime}\right)$, (e) outlet elastic radius $\left(h_{2}^{\prime \prime}\right)$, (f) elastic parameter $\left(t_{1}\right)$, (g) elastic parameter $\left(t_{2}\right)$, by Rubinow and Keller method.

Considering the change in radius of the elastic tube due to the peristaltic motion $\left(h^{\prime}\right)$ and elasticity of the tube $\left(h^{\prime \prime}\right)$, Eq. (26) takes the form

$$
\begin{aligned}
\sigma_{1}\left(p-p_{0}\right)= & \frac{\left(h^{\prime}+h^{\prime \prime}\right)\left(1+\lambda_{1}\right)}{12 \phi^{3}}\left[4\left(h^{\prime}+h^{\prime \prime}\right)^{2} \phi^{2}-3\left(h^{\prime}+h^{\prime \prime}\right)\right. \\
& \phi\left(1+2\left(h^{\prime}+h^{\prime \prime}\right) \phi\right)-6\left(1+2 \alpha\left(h^{\prime}+h^{\prime \prime}\right) \phi^{2}\right)- \\
& \left.6\left(1+2 \alpha\left(h^{\prime}+h^{\prime \prime}\right) \phi^{2}\right) \log \left(1-\left(h^{\prime}+h^{\prime \prime}\right) \phi\right)\right] .
\end{aligned}
$$

Since the flow is a Poiseuille flow, $h^{\prime \prime}=h^{\prime \prime}\left(p-p_{0}\right)$. On integrating Eq. (25) and setting $L=1$, we get

$$
\begin{aligned}
Q= & \int_{p_{2}-p_{0}}^{p_{1}-p_{0}}\left[\frac { ( h ^ { \prime } + h ^ { \prime \prime } ) ( 1 + \lambda _ { 1 } ) } { 1 2 \phi ^ { 3 } } \left[4\left(h^{\prime}+h^{\prime \prime}\right)^{2} \phi^{2}-\right.\right. \\
& 3\left(h^{\prime}+h^{\prime \prime}\right) \phi\left(1+2\left(h^{\prime}+h^{\prime \prime}\right) \phi\right)-6(1+2 \alpha \\
& \left.\left(h^{\prime}+h^{\prime \prime}\right) \phi^{2}\right)-6\left(1+2 \alpha\left(h^{\prime}+h^{\prime \prime}\right) \phi^{2}\right) \\
& \left.\left.\log \left(1-\left(h^{\prime}+h^{\prime \prime}\right) \phi\right)\right]\right] d p^{\prime},
\end{aligned}
$$

where $p^{\prime}=\left(p-p_{0}\right)$. If $h^{\prime \prime}\left(p^{\prime}\right)$ is known explicitly, then Eq. (28) can be solved by using the equilibrium condition as given below (Rubinow and Keller (1972))

$$
\frac{T\left(h^{\prime \prime}\right)}{h^{\prime \prime}}=p-p_{0}
$$




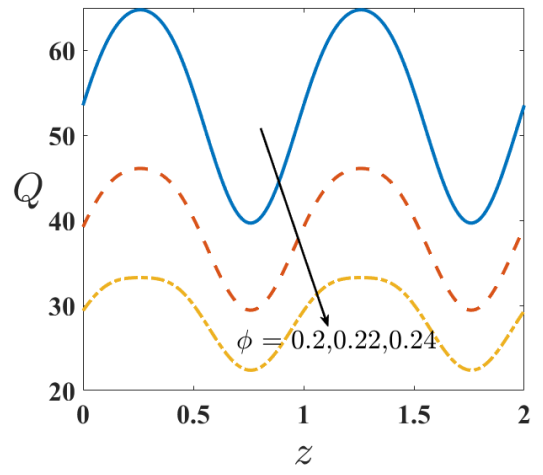

(a)

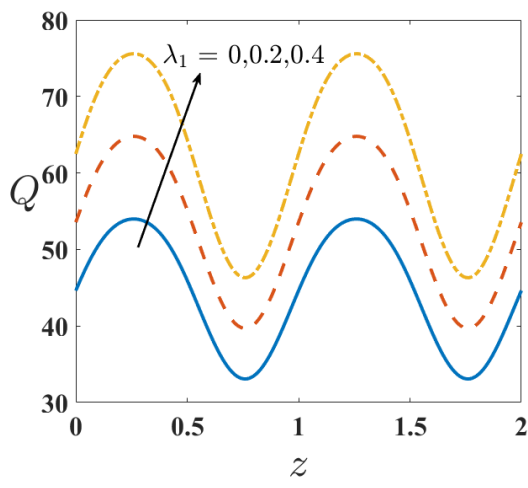

(b)

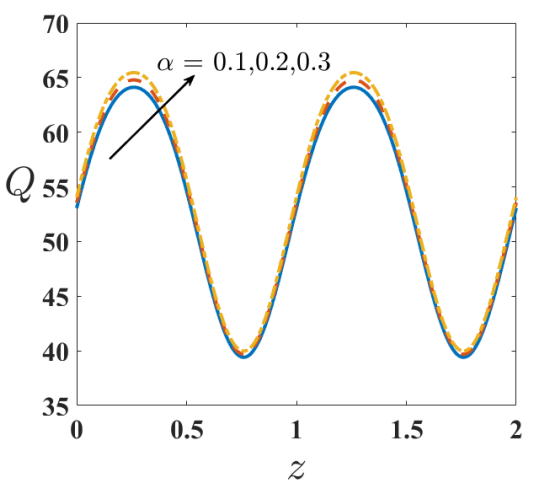

(c)

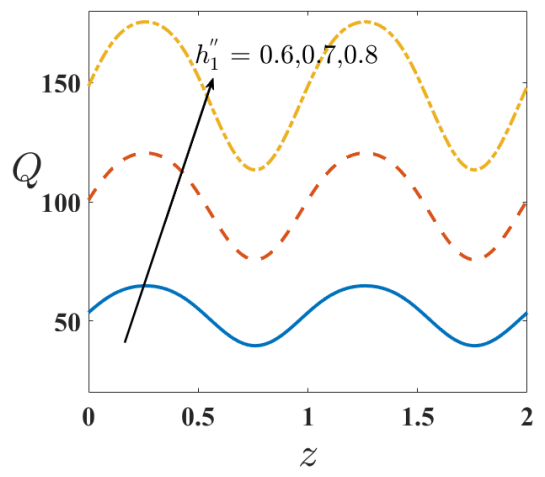

(d)

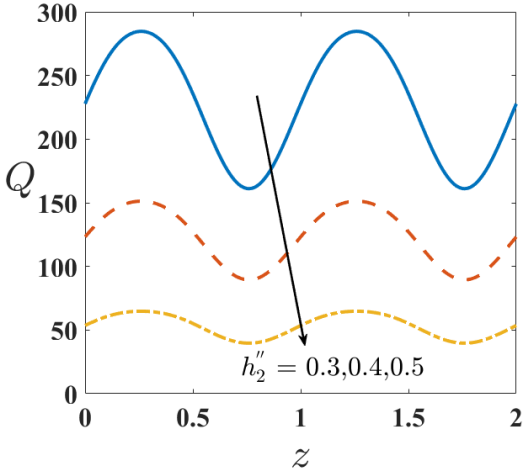

(e)

Fig. 3 Flux $(Q)$ for different values of (a) variable viscosity $(\phi)$, (b) Jeffrey parameter $\left(\lambda_{1}\right)$, (c) velocity slip parameter $(\alpha)$, (d) inlet elastic radius $\left(h_{1}^{\prime \prime}\right)$, (e) outlet elastic radius $\left(h_{2}^{\prime \prime}\right)$, by Mazumdar method.

\subsection{Application to flow of blood through an artery}

The flow of blood through an artery is found by two methods: Rubinow and Keller method and Mazumdar method.

\section{Rubinow and Keller method}

To know the relation between the tube radius and pressure, Roach and Burton (1959) obtained a tension versus length curve for a $4 \mathrm{~cm}$ long human iliac artery. The curve obtained was fit with the following equation by using the method of least squares (Rubinow and Keller (1972)).

$$
T\left(h^{\prime \prime}\right)=t_{1}\left(h^{\prime \prime}-1\right)+t_{2}\left(h^{\prime \prime}-1\right)^{5},
$$

where $t_{1}=13$ and $t_{2}=300$.

Substituting Eq. (30) in Eq. (29) and on differentiating, we get

$$
d p^{\prime}=\left[\frac{t_{1}}{h^{\prime \prime 2}}+t_{2}\left(4 h^{\prime \prime 3}-15 h^{\prime \prime 2}+20 h^{\prime \prime}-10+\frac{1}{h^{\prime 2}}\right)\right] d h^{\prime \prime} .
$$

This gives the theoretical determination of flux by Rubinow and Keller method.

\section{Mazumdar method}

As given by Mazumdar (1992), the tension relation is given by

$$
T\left(h^{\prime \prime}\right)=A\left(e^{K h^{\prime \prime}}-e^{K}\right),
$$

where $A=0.007435$ and $K=5.2625$.

Using Eq. (32) in Eq. (29) and differentiating, we obtain

$$
d p^{\prime}=A\left[e^{K h^{\prime \prime}}\left(\frac{K}{h^{\prime \prime}}-\frac{1}{h^{\prime \prime 2}}\right)+\frac{e^{K}}{h^{\prime \prime 2}}\right] d h^{\prime \prime} .
$$

The above equation is used to find the flux of a Jeffrey fluid through an elastic tube theoretically.

\section{RESULTS AND DISCUSSION}

The various parameters involved in the study are Jeffrey parameter $\left(\lambda_{1}\right)$, amplitude ratio $(\epsilon)$, velocity slip parameter $(\alpha)$, variable viscosity $(\phi)$, thermal conductivity $(\beta)$, elastic parameters $\left(t_{1}, t_{2}\right)$, inlet elastic radius $\left(h_{1}^{\prime \prime}\right)$, outlet elastic radius $\left(h_{2}^{\prime \prime}\right)$, Biot number $(\gamma)$ and Brinkman number $(N)$. The influence of these parameters on velocity $(w)$, temperature $(\theta)$, flow rate $(Q)$ (both by Rubinow and Keller method and Mazumdar method) and streamlines are analyzed and graphically represented in Figs. 2-8.

\subsection{Flux profiles}

The flux is determined by theoretical methods and computed through MATLAB.

\section{Rubinow and Keller method}

The graphical representations in Figs. 2(a)-2(g) illustrate the variation of pertinent parameters on theoretical flux as obtained from Rubinow and Keller method. From Fig. 2(a), it can be seen that an increase in the variation of $\phi$ results in decrease in the flux. Thus, the presence of variable viscosity plays a vital role in diminishing the flux. A rise in flux is observed in Figs. 2(b) and 2(c) for an increment in the values of $\lambda_{1}$ and $\alpha$ respectively. As seen from Fig. 2(d), the rise in the elastic radius of the tube at the inlet results in an increasing flux at any location along the axis of the tube. On the other hand, Fig. 2(e) suggests a drop in the flux with an increase in the outlet elastic radius of the tube. Furthermore, the increasing values of the elastic parameters of the tube are found to have an increasing effect on the flux (see Figs. 2(f) and 2(g)).

Mazumdar method

The effects of pertinent parameters on theoretical flux as obtained from 


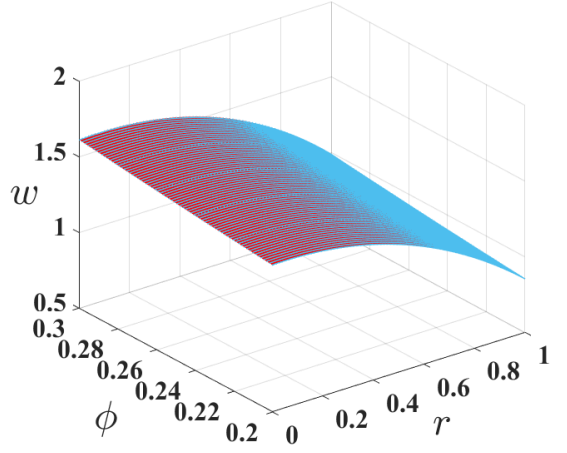

(a)

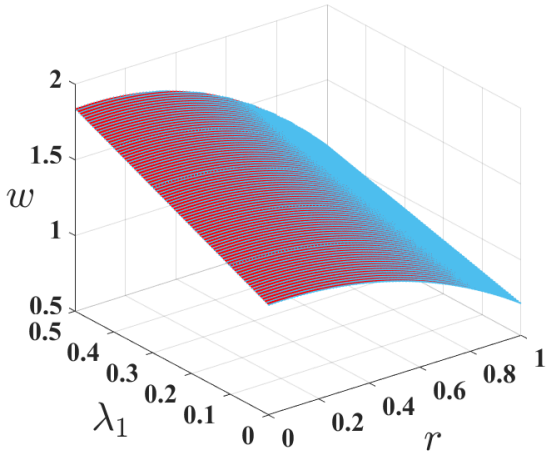

(b)

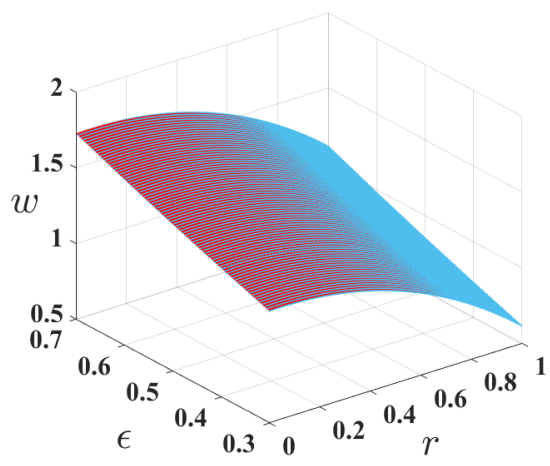

(d)

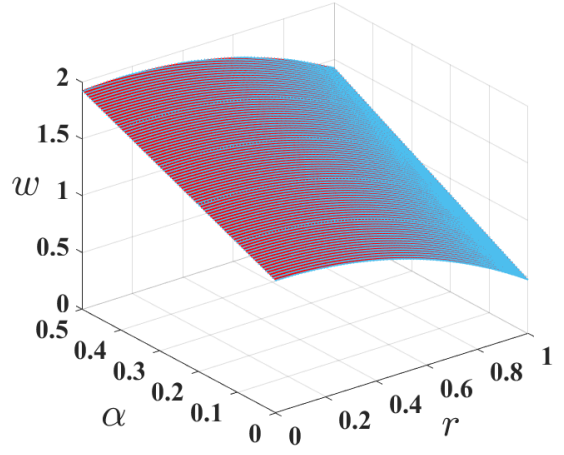

(c)

Fig. 4 Velocity profiles $(w)$ for different values of (a) variable viscosity $(\phi)$, (b) Jeffrey parameter $\left(\lambda_{1}\right)$, (c) velocity slip parameter $(\alpha)$, (d) amplitude ratio $(\epsilon)$.

Mazumdar method are sketched in Figs. 3(a) - 3(e). Figure 3(a) depicts the variation of $\phi$ on theoretical flux. Here an increase in the value of $\phi$ significantly reduces the volume of flux in an elastic tube. Figures 3(b) and 3(c) portray the influence of $\lambda_{1}$ and $\alpha$ on theoretical flux respectively. Here, an increase in the values of $\lambda_{1}$ and $\alpha$ enhances the volume flux. The variation of inlet and outlet elastic radius $h_{1}^{\prime \prime}$ and $h_{2}^{\prime \prime}$ on $Q$ are plotted in Figs. 3(d) and 3(e). For a fixed value of $h_{2}^{\prime \prime}$, the effect of increasing values of $h_{1}^{\prime \prime}$ enhances the flux (see Fig. 3(d)). However, Fig. 3(e) shows the opposite behavior when we fix $h_{1}^{\prime \prime}$ and vary $h_{2}^{\prime \prime}$.

\subsection{Comparative analysis}

In comparison, it can be noticed that flux is enhanced in Rubinow and Keller method than in the Mazumdar method. This behavior is expected due to the presence of fifth-degree polynomial present in the tensile relation defined by Rubinow and Keller (1972) rather than that of an exponential curve in the tensile relation given by Mazumdar (1992). In the absence of peristalsis, velocity slip and variable liquid properties, Eq. (28) reduces to that given by Rubinow and Keller (1972) for the flow of Newtonian fluid in an elastic tube. Further, the behavior of relevant parameters on theoretical flux obtained from both the models are in good agreement with the results of Vajravelu et al. (2015), Vajravelu et al. (2016) and Srinivas et al. (2017).

\subsection{Velocity and temperature profiles}

The velocity profiles with the radius of the tube for different values of $\phi, \lambda_{1}, \alpha$ and $\epsilon$ can be seen in Figs. 4(a)-4(d) respectively. It is observed that the velocity profiles are parabolic in nature with maximum velocity occuring at the center of the tube. An acceleration in the radial direction is observed for an increase in the values of each of these parameters.
Temperature variation with the radius of the tube is depicted in Figs. 5(a)5(e). From Fig. 5(a), it can be observed that a small variation in the values of $\phi$ results in a significant increase in the magnitude of temperature. An increase in the Jeffrey parameter $\lambda_{1}$ has a decreasing effect on temperature as seen in Fig. 5(b). The effect of $\beta$ on temperature is analyzed in Fig. 5(c). Here the temperature near the axis of the tube increases for higher values of $\beta$ and the effect is negligible near the walls. It is because of the reason that the higher values of $\beta$ allow the liquid to dissipate or absorb heat to its surroundings. Hence, the temperature decreases near the walls of the tube. The influence of $\gamma$ on temperature is portrayed in Fig. 5(d). Results indicate that the temperature profile is an increasing function of $\gamma$. Figure 5(e) elucidates the effect of $N$ on temperature. With an increment in $N(E c \times P r)$ the resulting temperature enhances. It is because of the viscous dissipation effects present in $E c$ which helps in enhancing the temperature profile. Further larger value of $\operatorname{Pr}$ diminishes the thermal conductivity and thereby enhances the temperature profile.

\subsection{Trapping phenomenon}

Trapping phenomena is the most important and well-known phenomena in peristalsis. It is the formation of a bolus in the tube, which is pushed in the forward direction by the sinusoidal wave movement of the peristaltic mechanism. These effects are illustrated in Figs. 6 - 8. These graphs indicate that an increase in the values of $\phi, \lambda_{1}$ and $\alpha$ result in an increase in the volume of the trapped bolus.

\section{CONCLUSIONS}

It is worth noticing that the results of a Newtonian model can be deduced from the current model by taking $\lambda_{1}=0$. The present study helps in 


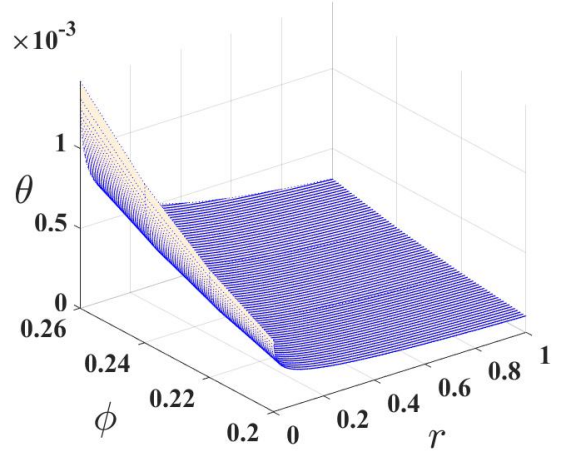

(a)

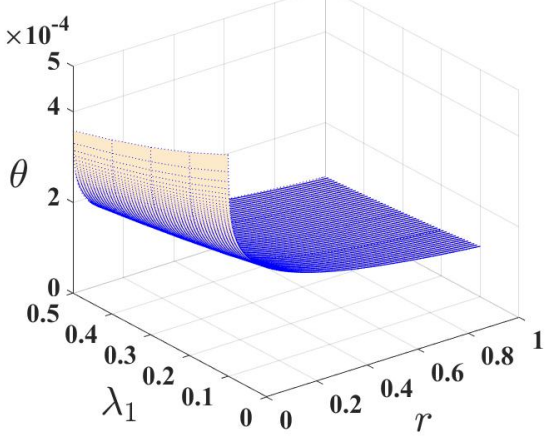

(b)

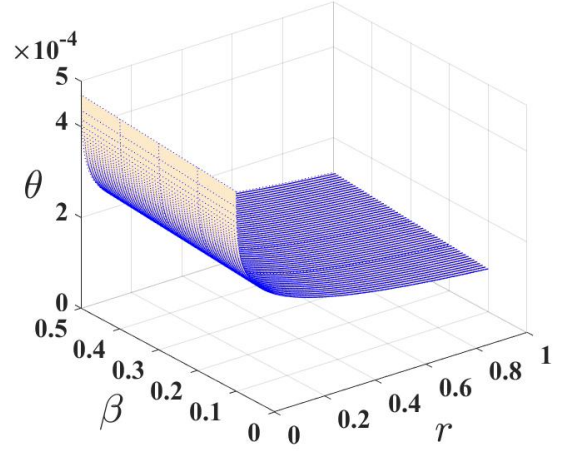

(c)

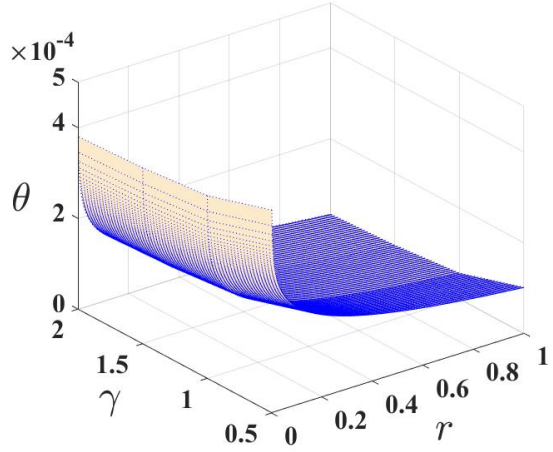

(d)

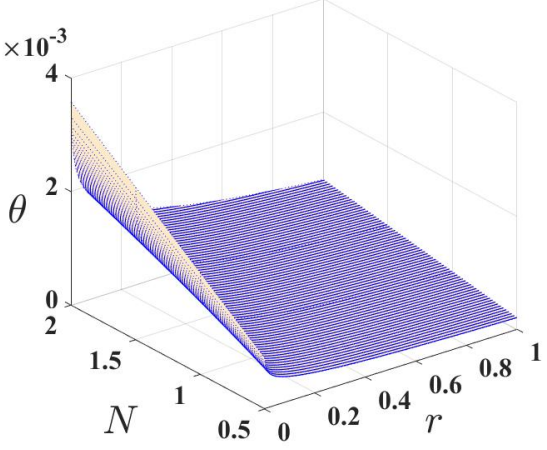

(e)

Fig. 5 Temperature profiles $(\theta)$ for different values of (a) variable viscosity $(\phi)$, (b) Jeffrey parameter $\left(\lambda_{1}\right)$, (c) thermal conductivity $(\beta)$, (d) Biot number $(\gamma),($ e) Brinkmann number $(N)$.
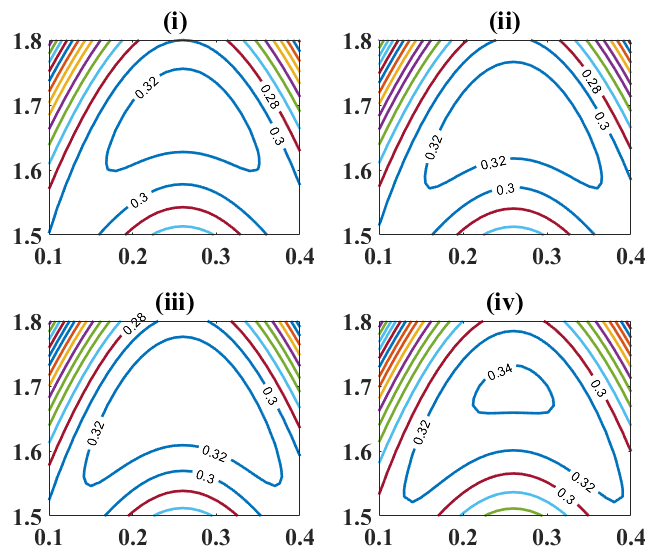

Fig. 6 Streamlines for different values of (i) $\phi=0.2$, (ii) $\phi=0.22$, (iii) $\phi=0.24$, (iv) $\phi=0.26$

understanding the flow of blood in arteries which can be handled and processed in the case of dysfunctions. The conclusions can be summarized as follows :

- The velocity field is an increasing function of $\phi, \lambda_{1}, \alpha$ and $\epsilon$.

- The presence of variable viscosity enhances the velocity and temperature in an elastic tube.

- Temperature of the fluid increases near the axis of the tube for an increasing value of $\beta$ and diminishes for larger values of $\lambda_{1}$.
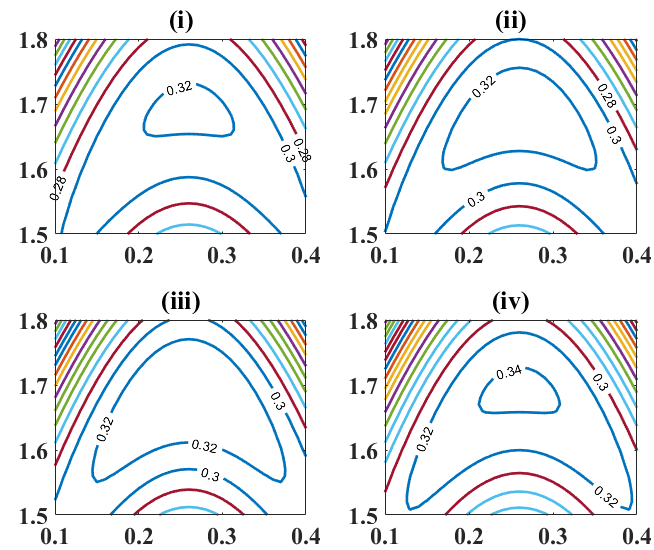

Fig. 7 Streamlines for different values of (i) $\lambda_{1}=0.1$, (ii) $\lambda_{1}=0.2$, (iii) $\lambda_{1}=0.3$, (iv) $\lambda_{1}=0.4$

- The volume flux is enhanced in Rubinow and Keller method than in the Mazumdar method and is found to be an increasing function of $\alpha$.

- The volume of trapped bolus increases for an increase in the value of $\phi, \lambda_{1}$ and $\alpha$. 

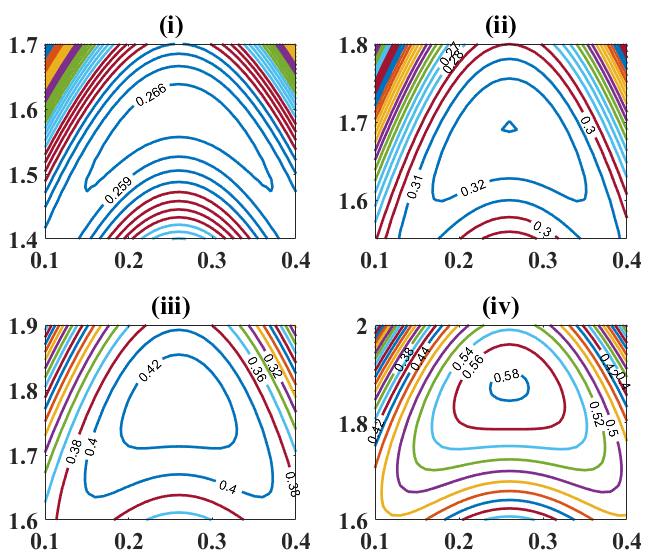

Fig. 8 Streamlines for different values of (i) $\alpha=0.1$, (ii) $\alpha=0.2$, (iii) $\alpha=0.3$, (iv) $\alpha=0.4$

\begin{tabular}{|c|c|}
\hline \multicolumn{2}{|c|}{ NOMENCLATURE } \\
\hline$N$ & Brinkman number \\
\hline$\rho$ & density of the fluid \\
\hline$z$ & dimensionless axial distance \\
\hline$w$ & dimensionless axial velocity \\
\hline$p$ & dimensionless pressure \\
\hline$u$ & dimensionless radial velocity \\
\hline$\psi$ & dimensionless streamline \\
\hline$E c$ & Eckert number \\
\hline$p_{0}$ & exterior pressure \\
\hline$T_{0}$ & initial temperature of the tube \\
\hline$p_{1}$ & inlet pressure \\
\hline$p_{2}$ & outlet pressure \\
\hline $\operatorname{Pr}$ & Prandtl number \\
\hline$r$ & radius of the tube \\
\hline$h^{\prime}(z, t)$ & radius of the tube due to peristalsis \\
\hline$h^{\prime \prime}(z)$ & radius due to elasticity of the tube \\
\hline$R e$ & Reynolds number \\
\hline$c_{p}$ & specific heat at constant pressure \\
\hline$T\left(h^{\prime \prime}\right)$ & tension in the tube wall \\
\hline$k$ & thermal conductivity \\
\hline$t$ & time \\
\hline$a$ & undeformed radius of the tube \\
\hline$Q$ & volumetric flow rate \\
\hline$q$ & volume flux \\
\hline$b$ & wave amplitude \\
\hline$c$ & wave speed \\
\hline \multicolumn{2}{|c|}{ Greek Symbols } \\
\hline$\epsilon$ & amplitude ratio \\
\hline$\gamma$ & Biot number \\
\hline$\beta$ & coefficient of thermal conductivity \\
\hline$\phi$ & coefficient of variable viscosity \\
\hline$\sigma_{1}$ & conductivity of the tube \\
\hline$\mu_{1}$ & constant of viscosity \\
\hline$\theta$ & dimensionless temperature \\
\hline$\lambda_{1}$ & Jeffrey parameter \\
\hline$\tau_{r z}$ & shear stress \\
\hline$k(\theta)$ & variable thermal conductivity \\
\hline$\alpha$ & velocity slip parameter \\
\hline$\mu(r)$ & viscosity varying with radius \\
\hline$\delta$ & wave number \\
\hline$\lambda$ & wave length \\
\hline
\end{tabular}

\section{REFERENCES}

Bhatti, M., and Abbas, M.A., 2016, "Simultaneous Effects of Slip and MHD on Peristaltic Blood Flow of Jeffrey Fluid Model Through a Porous Medium," Alexandria Engineering Journal, 55(2), 1017-1023. https://doi.org/10.1016/j.aej.2016.03.002.

Boulahia, Z., Wakif, A., and Sehaqui, R., 2018, "Heat Transfer and Cuwater Nanofluid Flow in a Ventilated Cavity Having Central Cooling
Cylinder and Heated From the Below Considering Three Different Outlet Port Locations," Frontiers in Heat and Mass Transfer, 11(11). http://dx.doi.org/10.5098/hmt.11.11 .

El Naby, A.E.H.A., El Misery, A., and El Shamy, I.I., 2004, "Effects of an Endoscope and Fluid with Variable Viscosity on Peristaltic Motion," Applied Mathematics and Computation, 158(2), 497-511. https://doi.org/10.1016/j.amc.2003.09.008.

Hayat, T., Ali, N., and Asghar, S., 2007, "An Analysis of Peristaltic Transport for Flow of a Jeffrey Fluid," Acta Mechanica, 193(1-2), 101112. https://doi.org/10.1007/s00707-007-0468-2.

Hayat, T., Hina, S., and Ali, N., 2010, "Simultaneous Effects of Slip and Heat Transfer on the Peristaltic Flow," Communications in Nonlinear Science and Numerical Simulation, 15(6), 1526-1537.

https://doi.org/10.1016/j.cnsns.2009.06.032.

Hayat, T., Nisar, Z., Yasmin, H., and Alsaedi, A., 2016, "Peristaltic Transport of Nanofluid in a Compliant Wall Channel with Convective Conditions and Thermal Radiation," Journal of Molecular Liquids, 220, 448453.

https://doi.org/10.1016/j.molliq.2016.04.080.

Hayat, T., Yasmin, H., Alhuthali, M.S., and Kutbi, M.A., 2013, "Peristaltic Flow of a Non-Newtonian Fluid in an Asymmetric Channel with Convective Boundary Conditions," Journal of Mechanics, 29(4), 599607.

https://doi.org/10.1017/jmech.2013.28.

Hayat, T., and Ali, N., 2008, "Effect of Variable Viscosity on the Peristaltic Transport of a Newtonian Fluid in an Asymmetric Channel," Applied Mathematical Modelling, 32(5), 761-774.

https://doi.org/10.1016/j.apm.2007.02.010.

Javed, M., Hayat, T., Mustafa, M., and Ahmad, B., 2016, "Velocity and Thermal Slip Effects on Peristaltic Motion of Walters-B Fluid," International Journal of Heat and Mass Transfer, 96, 210-217. https://doi.org/10.1016/j.ijheatmasstransfer.2015.12.029.

Latham, T.W., 1966, Fluid Motions in a Peristaltic Pump, Ph.D. thesis, Massachusetts Institute of Technology.

Manjunatha, G., and Choudhary, R.V., 2018, "Slip Effects on Peristaltic Transport of Casson Fluid in an Inclined Elastic Tube with Porous Walls," Journal of Advanced Research in Fluid Mechanics and Thermal Sciences, 43(1), 67-80.

Mazumdar, J.N., 1992, Biofluid Mechanics, World Scientific.

Mebarek-Oudina, F., and Bessaih, R., 2016, "Oscillatory Magnetohydrodynamic Natural Convection of Liquid Metal Between Vertical Coaxial Cylinders," J Appl Fluid Mech, 9(4), 1655-1665.

https://doi.org/10.18869/acadpub.jafm.68.235.24813.

Mebarek-Oudina, F., 2017, "Numerical Modeling of the Hydrodynamic Stability in Vertical Annulus with Heat Source of Different Lengths," Engineering Science and Technology, an International Journal, 20(4), 1324-1333.

https://doi.org/10.1016/j.jestch.2017.08.003.

Mernone, A., Mazumdar, J., and Lucas, S., 2002, "A Mathematical Study of Peristaltic Transport of a Casson Fluid," Mathematical and Computer Modelling, 35(7-8), 895-912.

http://educ.jmu.edu/ lucassk/Papers/mernone.pdf. 
Munir, A.F., Tasawar, H., and Bashir, A., 2014, "Peristaltic Flow in an Asymmetric Channel with Convective Boundary Conditions and Joule Heating," Journal of Central South University, 21(4), 1411-1416. https://doi.org/10.1007/s11771-014-2079-0.

Prasad, K., Vaidya, H., Vajravelu, K., and Ramanjini, V., 2018b, "Analytical Study of Cattaneo-Christov Heat Flux Model for WilliamsonNanofluid Flow Over a Slender Elastic Sheet with Variable Thickness," Journal of Nanofluids, 7(3), 583-594.

https://doi.org/10.1166/jon.2018.1475.

Prasad, K., Vajravelu, K., Vaidya, H., Basha, N.Z., and Umesh, V., 2017, "Thermal and Species Concentration of MHD Casson Fluid at a Vertical Sheet in the Presence of Variable Fluid Properties," Ain Shams Engineering Journal.

https://doi.org/10.1016/j.asej.2016.08.017.

Prasad, K., Vajravelu, K., Vaidya, H., Rashidi, M., and Neelufer, Z.B., 2018a, "Flow and Heat Transfer of a Casson Liquid over a Vertical Stretching Surface: Optimal Solution," American Journal of Heat and Mass Transfer, 5(1), 1-22.

http://paper.uscip.us/ajhmt/ajhmt.2018.1001.pdf.

Rajashekhar, C., Manjunatha, G., Prasad, K., Divya, B., and Vaidya, H., 2018a, "Peristaltic Transport of Two-Layered Blood Flow Using Herschel-Bulkley Model," Cogent Engineering, 5(1), 1-16. https://doi.org/10.1080/23311916.2018.1495592.

Rajashekhar, C., Manjunatha, G., Vaidya, H., Divya, B., and Prasad, K., 2018b, "Peristaltic Flow of Casson Liquid in an Inclined Porous Tube with Convective Boundary Conditions and Variable Liquid Properties," Frontiers in Heat and Mass Transfer, 11(35). http://dx.doi.org/10.5098/hmt.11.35 .

Rajashekhar, C., Manjunatha, G., Vaidya, H., and Prasad, K.V., 2018c, "Peristaltic Flow of Herschel-Bulkley Fluid in an Elastic Tube with Slip at Porous Walls," Journal of Advanced Research in Fluid Mechanics and Thermal Sciences, 52(1), 63-75.

Roach, M.R., and Burton, A.C., 1959, "The Effect of Age on the Elasticity of Human Iliac Arteries," Canadian journal of biochemistry and physiology, 37(4), 557-570.

https://doi.org/10.1139/o59-059.

Rubinow, S., and Keller, J.B., 1972, "Flow of a Viscous Fluid Through an Elastic Tube with Applications to Blood Flow," Journal of theoretical biology, 35(2), 299-313.

https://doi.org/10.1016/0022-5193(72)90041-0.

Sankad, G., and Patil, A., 2018, "Heat Transfer Inferences on the Herschel Bulkley Fluid Flow Under Peristalsis," Frontiers in Heat and Mass Transfer, 10(17).

http://dx.doi.org/10.5098/hmt.10.17.

Selvi, C., Haseena, C., Srinivas, A., and Sreenadh, S., 2017, "The Effect of Heat Transfer on Peristaltic Flow of Jeffrey Fluid in an Inclined Porous Stratum," IOP Conference Series: Materials Science and Engineering, vol. 263, 062027, IOP Publishing.
Sinha, A., Shit, G., and Ranjit, N., 2015, "Peristaltic Transport of MHD Flow and Heat Transfer in an Asymmetric Channel: Effects of Variable Viscosity, Velocity-slip and Temperature Jump," Alexandria Engineering Journal, 54(3), 691-704.

https://doi.org/10.1016/j.aej.2015.03.030.

Srinivas, A., Selvi, C., and Sreenadh, S., 2017, "Peristaltic Pumping of a Generalized Newtonian Fluid in an Elastic Tube," Journal of Applied Fluid Mechanics, 10(6).

Srivastava, L., Srivastava, V., and Sinha, S., 1983, "Peristaltic Transport of a Physiological Fluid," Biorheology, 20(2), 153-166.

https://doi.org/10.3233/BIR-1983-20205.

Vaidya, H., Gudekote, M., Choudhari, R., and KV, P., 2018b, "Role of Slip and Heat Transfer on Peristaltic Transport of Herschel-Bulkley Fluid Through an Elastic Tube," Multidiscipline Modeling in Materials and Structures, 14(5), 940-959.

https://doi.org/10.1108/MMMS-11-2017-0144.

Vaidya, H., Rajashekhar, C., Manjunatha, G., and Prasad, K., 2018a, "Rheological Properties and Peristalsis of Rabinowitsch Fluid Through Compliant Porous Walls in an Inclined Channel," Journal of Nanofluids, 8(5), 970-979.

https://doi.org/10.1166/jon.2019.1664.

Vajravelu, K., Sreenadh, S., Devaki, P., and Prasad, K., 2015, "Peristaltic Transport of a Herschel-Bulkley Fluid in an Elastic Tube," Heat Transfer - Asian Research, 44(7), 585-598.

https://doi.org/10.1002/htj.21137.

Vajravelu, K., Sreenadh, S., Devaki, P., and Prasad, K., 2016, "Peristaltic Pumping of a Casson Fluid in an Elastic Tube," Journal of Applied Fluid Mechanics, 9(4), 1897-1905.

https://doi.org/10.18869/acadpub.jafm.68.235.24695.

Wakif, A., Boulahia, Z., Ali, F., R. Eid, M., and Sehaqui, R., 2018b, "Numerical Analysis of the Unsteady Natural Convection MHD Couette Nanofluid Flow in the Presence of Thermal Radiation Using Single and Two-Phase Nanofluid Models for Cu-Water Nanofluids," International Journal of Applied and Computational Mathematics, 4(3), 81. https://doi.org/10.1007/s40819-018-0513-y.

Wakif, A., Boulahia, Z., Mishra, S., Rashidi, M.M., and Sehaqui, R., 2018c, "Influence of a Uniform Transverse Magnetic Field on the Thermo-hydrodynamic Stability in Water-based Nanofluids with Metallic Nanoparticles Using the Generalized BuongiornoâĂŹs Mathematical Model," The European Physical Journal Plus, 133(5), 181. https://doi.org/10.1140/epjp/i2018-12037-7.

Wakif, A., Boulahia, Z., and Sehaqui, R., 2018a, "A Semianalytical Analysis of Electro-thermo-hydrodynamic Stability in Dielectric Nanofluids Using BuongiornoâĂŹs Mathematical Model Together with More Realistic Boundary Conditions," Results in Physics, 9, 14381454.

https://doi.org/10.1016/j.rinp.2018.01.066. 